Journal Homepage: http://pusdikra-publishing.com/index.php/jrss

\title{
PENGARUH LATAR BELAKANG DAN PENGALAMAN PENDIDIK TERHADAP PENINGKATAN PEMBELAJARAN DI MIS DARUL YATAMA PANGKALAN BRANDAN
}

\author{
Suharmin', Muammar Al Qadri², Azhar ${ }^{3}$ \\ 1,2,3,STAI Jam'iyah Mahmudiyah
}

\begin{tabular}{|c|c|}
\hline & ABSTRACT \\
\hline & $\begin{array}{l}\text { The Effect of Educator's Background and Experience on Improving } \\
\text { Learning at MIS DARUL YATAMA Pangkalan Brandan. The purposes of } \\
\text { this study are 1) To find out the background to the improvement of } \\
\text { learning at MIS DARUL YATAMA Pangkalan Brandan 2) To find out the } \\
\text { experience of educators to the improvement of learning at MIS DARUL } \\
\text { YATAMA Pangkalan Brandan. This research uses } 3 \text { stages, namely; the } \\
\text { research instrument preparation stage, the research instrument trial stage, } \\
\text { the research implementation stage. The subjects of this research were the } \\
\text { teachers and students of MIS DARUL YATAMA Pangkalan Brandan. } \\
\text { Data collection techniques used interviews, observations, document } \\
\text { research, literature studies and questionnaires/questionnaires. The Effect } \\
\text { of Educator's Background and Experience on Improving Learning at MIS } \\
\text { Darul Yatama Pangkalan Brandan which has an average result of } 55.63 \text {, a } \\
\text { median of } 54.17 \text {, a mode of } 50.5 \text {, a variant of } 91.32 \text { and a standard } \\
\text { deviation of 9.55 acceptable with a good tolerance signification limit and } \\
\text { meets the criteria . The Effect of Educator's Background and Experience } \\
\text { on Improving Learning at MIS Darul Yatama Pangkalan Brandan has an } \\
\text { average result of } 66.27 \text {, a median of } 56.62 \text {, a mode of } 58.06 \text {, a variant of } \\
28.27 \text { and a standard deviation of } 5.32 \text { accepted with a tolerance } \\
\text { significance limit. There is a significant relationship between the influence } \\
\text { of the background and experience of educators on improving learning at } \\
\text { MIS Darul Yatama Pangkalan Brandan with the results of Fcount = } 10,903 \\
\text { and Ftable (1.31) ( } 0.01 \text { ) = } 7.53 \text { which can be concluded Fcount } \geq \text { Ftable by } \\
\text { accepting Ha and rejecting H0 with the equation of the line regression of } \\
49.55+0.29 \text { X. }\end{array}$ \\
\hline Nata & cators, Learning Improvement. \\
\hline
\end{tabular}

\section{PENDAHULUAN}

Guru atau pendidik adalah orang yang bertanggung jawab terhadap perkembangan peserta didiknya dengan upaya mengembangkan berbagai potensi yang dimiliki peserta didik tersebut. Guru adalah orang yang paling berpengaruh terhadap peserta didiknya, di sekolah guru akan menjadi panutan atau contoh bagi peserta didiknya. 
Menurut Kunandar, salah satu komponen penting dalam pendidikan adalah guru. Guru dalam konteks pendidikan mempunyai peranan yang besar dan strategis. Hal ini disebabkan gurulah yang berada di barisan terdepan dalam pelaksanaan pendidikan. Gurulah yang langsung berhadapan dengan peserta didik untuk mentransfer ilmu pengetahuan dan teknologi sekaligus mendidik dengan nilai-nilai positif melalui bimbingan dan keteladanan (Kunandar 2010).

Dari hal di atas Kunandar juga menjelaskan bahwa guru mempunyai misi dan tugas yang berat, namun mulai dalam mengantarkan tunastunas bangsa ke puncak cita-cita. Oleh karena itu, sudah selayaknya guru mempunyai berbagai kompetensi yang berkaitan dengan tugas dan tanggung jawabnya. Dengan kompetensi tersebut, maka akan menjadi guru yang profesional, baik secara akademis maupun non Akademis.

Dari penjelasan di atas dapat diketahui bahwa guru merupakan unsur yang sangat penting dalam dunia pendidikan, karena tanpa adanya guru maka suatu pendidikan tidak akan dapat dikatakan berhasil. Seorang guru dikatakan memiliki tugas yang berat dalam dunia pendidikan, untuk itu guru tidak hanya dituntut mampu menguasai bahan ajar, melainkan guru itu juga harus mampu memahami peserta didik, mampu merancang dan melaksanakan pembelajaran, mampu mengevaluasi hasil belajar, dan mampu mengembangkan peserta didik untuk mengaktualisasikan berbagai potensi yang dimilikinya, yang mana semua itu dapat diperoleh seorang guru apabila menguasai kompetensi guru. Jadi, seorang guru dapat melaksanakan pendidikan dengan baik apabila telah menguasai kompetensi guru.

Adapun sepuluh kemampuan dasar guru itu menurut Syaiful Sagala adalah:

1. Kemampuan menguasai bahan pelajaran yang disajikan,

2. Kemampuan mengelola program belajar mengajar,

3. Kemampuan mengelola kelas,

4. Kemampuan menggunakan media/sumber belajar,

5. Kemampuan menguasai landasan-landasan kependidikan,

6. Kemampuan mengelola interaksi belajar mengajar,

7. Kemampuan menilai prestasi peserta didik untuk kependidikan pengajaran,

8. Kemampuan mengenal fungsi dan program pelayanan bimbingan dan penyuluhan,

9. Kemampuan mengenal dan menyelenggarakan administrasi sekolah, dan 
10. Kemampuan memahami prinsip-prinsip dan menafsirkan hasilhasil penelitian pendidikan guna keperluan pengajaran (Sagala, 2013).

Dengan adanya perundang-undangan yang mengatur tentang kompetensi guru, menunjukkan bahwa eksistensi kompetensi guru itu tidak hanya sebagai aturan atau syarat untuk dapat melaksanakan pendidikan saja, melainkan juga untuk menunjukkan bahwa menguasai kompetensi guru itu sangat penting dalam memajukan mutu dunia pendidikan dan dianjurkan bagi seorang guru untuk memilikinya.

Syaiful Sagala juga menjelaskan dalam tulisannya, pengembangan dan peningkatan kualitas kompetensi guru selama ini diserahkan pada guru itu akan berkualitas, karena ia senantiasa mencari peluang untuk meningkatkan kualitasnya sendiri. Idealnya pemerintah, asosiasi pendidikan dan guru, serta satuan pendidikan memfasilitasi guru untuk mengembangkan kemampuan bersifat kognitif berupa pengertian dan pengetahuan, afektif berupa sikap dan nilai, maupun performansi berupa perbuatan-perbuatan yang mencerminkan pemahaman keterampilan dan sikap. Dukungan yang demikian itu penting, karena dengan cara itu akan meningkatkan kemampuan pedagogik bagi guru.

Untuk dapat melaksanakan pendidikan yang baik dan mendapat predikat berhasil dalam mengajar, seorang guru dapat melakukannya dengan peningkatan kualitas penguasaan kompetensi guru terutama kompetensi pedagogik. Untuk pengembangan kualitas penguasaan kompetensi tersebut telah difasilitasi seperti yang telah dipaparkan di atas, hanya tinggal keinginan gurunya saja apakah mampu atau tidak untuk memanfaatkan dukungan atau fasilitas yang telah disediakan tersebut untuk meningkatkan kemampuan kompetensi pedagogiknya.

Siti Suwadah Rimang menjelaskan bahwa, tugas utama pendidikan terhadap anak didik di sekolah adalah membangun jiwa mereka agar siap menerima berbagai pelajaran dan kelak mengaplikasikan ilmu yang mereka peroleh demi kebaikan sesama. Guru merupakan ujung tombak pelaksana pendidikan sekolah. Maju mundurnya kualitas pendidikan sangat dipengaruhi oleh kualitas guru. Untuk memperoleh murid dengan sumber daya manusia yang tinggi maka dibutuhkan guru yang memiliki sumber daya manusia yang tinggi pula (Rimang, 2011).

Menurut kutipan yang diambil Kunandar, upaya peningkatan mutu pendidikan dilakukan dengan berbagai pendekatan, baik pendekatan kelembagaan, legal formal, maupun pemberdayaan sumber daya 
pendidikan. Pendekatan kelembagaan salah satunya melalui lahirnya Direktorat Jenderal Peningkatan Mutu Pendidik dan Tenaga Kependidikan (Ditjen PMPTK). Pendekatan legal formal melalui serangakaian perundang-undangan (peraturan) yang berkaitan dengan pendidikan, seperti UU Nomor 20 Tahun 2003 tentang Sistim Pendidikan Nasional, Peraturan Pemerintah Nomor 19 Tahun 2005 tentang Standar Nasional Pendidikan, dan UU Nomor 14 Tahun 2005 tentang Guru dan Dosen. Pendekatan pemberdayaan sumber daya pendidikan dilakukan dengan melakukan kegiatan peningkatan kompetensi dan kualifikasi tenaga pendidik dan kependidikan secara sistimatis dan berkesinambungan.

Dengan adanya berbagai upaya pendekatan untuk memperbaiki mutu pendidikan ini masalah di dunia kependidikan dapat berkurang. Dalam pelaksanaannya dilakukan dengan secara sistimatis dan berkisinambungan seperti yang disebutkan di atas, sehingga upaya pendekatan ini dapat terlaksana dengan baik.

Dalam mempraktikkan upaya memperbaiki mutu pendidikan dapat dilakukan guru dengan melakukan proses pendekatan dengan peserta didik ketika melaksanakan pembelajaran di mana pada saat itulah terjadi komunikasi antara guru dan peserta didik.

Menurut Abuddin Nata, proses belajar mengajar secara sederhana dapat diartikan sebagai kegiatan interaksi dan saling memengaruhi antara pendidik dan peserta didik, dengan fungsi utama pendidik memberikan materi pelajaran atau sesuatu yang memengaruhi peserta didik, sedangkan peserta didik menerima pelajaran, pengaruh atau sesuatu yang diberikan oleh pendidik (Nata, 2010). Sedangkan menurut Nurhasnawati, proses pembelajaran merupakan kegiatan melaksanakan kurikulum suatu lembaga pendidikan guna untuk mempengaruhi peserta didik agar mereka dapat mencapai tujuan dan standar kompetensi yang telah ditetapkan dalam kurikulum. Proses pembelajaran dapat dipandang sebagai suatu proses komunikasi dengan pengertian bahwa pesan pembelajaran yang disampaikan oleh guru dapat diterima (diserap) dengan baik atau dapat dikatakan menjadi "milik" muridmurid (Nurhasnawati, 2011).

Proses belajar mengajar merupakan salah satu cara untuk melakukan pendekatan antara guru dengan siswa. Dengan adanya ini akan mempermudah seorang guru untuk mencapai tujuan dan standar kompetensi yang ditetapkan dalam kurikulum, karena guru terhubung langsung dengan siswanya dalam menyampaikan bahan ajar tersebut. 
Siti Suwadah Rimang menegaskan, bahwa kemuliaan hati seorang guru diwujudkan dalam kehidupan sehari-hari bukan di depan kelas atau pada torehan angka di atas kertas yang kita sebut rapor. Guru atau dosen secara nyata dapat berbagi dengan anak didiknya. Dan hal ini tidaklah sulit untuk diwujudkan karena semuanya ada pada seorang, guru/atau dosen memiliki daya kalbu yang tinggi yang menampilkan kepribadian yang paripurna, yang di dalamnya terdapat daya spiritual, emosional, moral, rasa kasih sayang, kesopanan, toleransi, kejujuran, dan kebersihan, disiplin diri, harga diri, tanggung jawab, estetika, etika, kerajinan, dan komitmen terhadap pekerjaan.

Dalam proses pembelajaran berlangsung masih terdapat gejalagejala yang menghambat tercapainya tujuan pembelejaran. Dengan melihat gejala tersebut penulis merasa tertarik untuk melakukan penelitian dengan judul: "Pengaruh Latar Belakang dan Pengalaman Pendidik Terhadap Peningkatan Pembelajaran di MIS Darul Yatama Pangkalan Brandan".

\section{METODE PENELITIAN}

Dalam penelitian Pengaruh Latar Belakang dan Pengalaman Pendidik Terhadap Peningkatan Pembelajaran di MIS Darul Yatama Pangkalan Brandan dilakukan melalui pendekatan kuantitatif. Dengan demikian data akan disajikan dalam bentuk angka dan menggunakan statistik regresi sederhana.

Penelitian kuantitatif ini dilakukan dengan prosedur yang melalui tahap alur kerja penelitian yang diawali dengan studi pendahuluan untuk merumuskan identifikasi masalah, Pembatasan masalah, merumuskan masalah dan studi literatur yang pada akhirnya diperoleh perangkat penelitian berupa bahan ajar, pendektan pembelajaran, instrumen peneitian. Perangkat penelitian ini sebelum di uji cobakan telah dilakukan validasi agar penelitian yang dilakukan memiliki hasil yang baik. penelitian juga memperhatikan prosedur dalam menentukan desan penelitian dan tehnik pengumpulan data penelitian yang pada akhirnya memberikan kesimpulan dan saran serta implikasi penelitian.

\section{HASIL DAN PEMBAHASAN}

Pada hasil penelitian akan diberikan seluruh jawaban yang dimulai dari rumusan masalah kepada hipotesis penelitian yang akan menjadi suatu pretanyaan dalam suatu penelitian yang akan diuji dengan cara kuantitatif dan juga kualitatif untuk mendapatkan kejadian yang 
dihadapai dalam penelitian yang merupakan hipotesis penelitian. Data yang telah di dipatkan telah dibentuk dalam statistik deskriptif dan juga melalui uji persyaratan data yang telah diberikan pada sub bahasan sebelumnya yang dijabarkan pada bab terdahulu.

Selanjutnya setelah dipaparkan data secara kualitatif maka akan dipaparkan juga secara kuantitatif terhadap penelitian tentang pengaruh latar belakang dan pengalaman pendidik. Dari hasil perhitungan dengan menggunakan alat bantu dari softwere Excel maka di dapat data tentang pengaruh latar belakang dan pengalaman pendidik untuk meningkatkan pembelajaran pada siswa dengan menggunakan batas toleransi untuk menerima atau menolak pengajuan hipotesis secara statistik dekriptif yaitu:

Tabel 1. Uji Statistik Deskriptif

\begin{tabular}{|l|l|l|l|l|l|}
\hline $\begin{array}{c}\text { Hasil Statistik } \\
\text { Deskriptif penggunaan } \\
\text { model SFE }\end{array}$ & \multicolumn{5}{|c|}{ Batas Toleransi Penerimaan Uji Statisitk } \\
\hline Mean & 55.63 & $45 \leq \mathrm{X} \leq 100$ & Diterima & $0 \leq \mathrm{X} \leq 44$ & Ditolak \\
\hline Median & 54.17 & $\begin{array}{l}45 \leq \text { Med } \leq \\
100\end{array}$ & Diterima & $\begin{array}{l}0 \leq \\
\text { Med } \leq 44\end{array}$ & Ditolak \\
\hline Modus & 50.5 & $\begin{array}{l}45 \leq \text { Mod } \leq \\
100\end{array}$ & Diterima & $\begin{array}{l}0 \leq \\
\text { Mod } \leq 44\end{array}$ & Ditolak \\
\hline Varians & 91.32 & $\begin{array}{l}25 \leq \mathrm{S}^{2} \leq \\
100\end{array}$ & Diterima & $0 \leq \mathrm{S}^{2} \leq 24$ & Ditolak \\
\hline $\begin{array}{l}\text { Standart } \\
\text { deviasi }\end{array}$ & 9.55 & $5 \leq \mathrm{S} \leq 10$ & Diterima & $0 \leq \mathrm{S} \leq 4$ & Ditolak \\
\hline
\end{tabular}

Sumber Nifisaky, 2016: 65

Setelah melihat batas toleransi penerimaan uji statistik deskriptif maka dapat disimpulkan bahwa data angket tentang pengaruh latar belakang dan pengalaman pendidik dapat diterima dengan batas signifikasi toleransi.

Selanjutnya juga dipaparkan data peningkatan pembelajaran, dari hasil perhitungan yang dilakukan menggunakan batas toleransi untuk menerima atau menolak pengajuan hipotesis secara statistik dekriptif. Adapun data yang didapat sebagai berikut: 
Tabel 2. Uji Statistik Deskriptif

\begin{tabular}{|l|l|l|l|l|l|}
\hline $\begin{array}{c}\text { Hasil Statistik } \\
\text { Deskriptif peningkatan } \\
\text { pembelajaran }\end{array}$ & \multicolumn{5}{|c|}{ Batas Toleransi Penerimaan Uji Statisitk } \\
\hline Mean & 66.27 & $45 \leq \mathrm{X} \leq 100$ & $\begin{array}{l}\text { Diterim } \\
\text { a }\end{array}$ & $0 \leq \mathrm{X} \leq 44$ & $\begin{array}{l}\text { Ditola } \\
k\end{array}$ \\
\hline Median & 56,62 & $\begin{array}{l}45 \leq \text { Med } \leq \\
100\end{array}$ & $\begin{array}{l}\text { Diterim } \\
\text { a }\end{array}$ & $\begin{array}{l}0 \leq \\
\text { Med } \leq 44\end{array}$ & $\begin{array}{l}\text { Ditola } \\
k\end{array}$ \\
\hline Modus & 58.06 & $\begin{array}{l}45 \leq \text { Mod } \leq \\
100\end{array}$ & $\begin{array}{l}\text { Diterim } \\
\text { a }\end{array}$ & $\begin{array}{l}0 \leq \\
\text { Mod } \leq 44\end{array}$ & $\begin{array}{l}\text { Ditola } \\
k\end{array}$ \\
\hline Varians & 28.27 & $25 \leq S^{2} \leq 100$ & $\begin{array}{l}\text { Diterim } \\
\text { a }\end{array}$ & $0 \leq S^{2} \leq 24$ & $\begin{array}{l}\text { Ditola } \\
k\end{array}$ \\
\hline $\begin{array}{l}\text { Standart } \\
\text { deviasi }\end{array}$ & 5.32 & $5 \leq \mathrm{S} \leq 10$ & $\begin{array}{l}\text { Diterim } \\
\text { a }\end{array}$ & $\begin{array}{l}\text { Ditola } \\
k\end{array}$ \\
\hline
\end{tabular}

Sumber Nifisaky, 2016: 65

Setelah melihat batas toleransi penerimaan uji statistik deskriptif maka dapat disimpulkan bahwa data kemampuan evaluasi dan kerja kelompok siswa dapat diterima dengan batas signifikasi toleransi.

Temuan hasil penelitian berikut ini adalah berdasarkan hasil-hasil yang diperoleh dalam pengujian hipotesis dan analisis data angket pengaruh latar belakang dan pengalaman pendidik terhadap peningkatan pembelajaran di MIS DARUL YATAMA PANGKALAN BRANDAN maka temuan di dalam penelitian ini adalah terdapat pengaruh yang positif dan signifikan antara latar belakang dan pengalaman pendidik terhadap peningkatan pembelajaran. pengaruh latar belakang dan pengalaman pendidik yang dilakukan dengan baik akan mempengaruhi peningkatan pembelajaran siswa dan sebaliknya.

\section{KESIMPULAN}

Pendidikan adalah suatu usaha sadar untuk menyiapkan peserta didik agar berperan aktif dan positif dalam hidupnya sekarang dan yang akan datang, dan pendidikan nasional Indonesia adalah pendidikan yang berakar pada pencapaian tujuan pembangunan nasional Indonesia. Berdasarkan hasil deskripsi data, uji persyaratan analisis, hasil penelitian, temuan penelitian dan keterbatasan penelitian maka peneliti memperoleh kesimpulan sebagai berikut:

1. Pengaruh Latar Belakang dan Pengalaman Pendidik Terhadap Peningkatan Pembelajaran di MIS Darul Yatama Pangkalan Brandan yang memiliki hasil rataan sebesar 55.63, median sebesar 
54.17, modus sebesar 50.5 varian sebesar 91.32 dan simpangan baku sebesar 9,55 dapat diterima dengan batas signifikasi toleransi yang baik dan memenuhi kriteria.

2. Pengaruh Latar Belakang dan Pengalaman Pendidik Terhadap Peningkatan Pembelajaran di MIS Darul Yatama Pangkalan Brandan memiliki hasil rataan sebesar 66.27, median sebesar 56.62, modus sebesar 58.06 varian sebesar 28.27 dan simpangan baku sebesar 5.32 diterima dengan batas signifikasi toleransi.

3. Terdapat hubungan yang signifikan antara Pengaruh Latar Belakang dan Pengalaman Pendidik Terhadap Peningkatan Pembelajaran di MIS Darul Yatama Pangkalan Brandan dengan hasil $\mathrm{F}_{\text {hitung }}=10.903$ dan $F_{\text {tabel (1.31) (0.01) }}=7.53$ yang dapat disimpulkan $F_{\text {hitung }} \geq F_{\text {tabel }}$ dengan menerima $\mathrm{H}_{\mathrm{a}}$ dan menolak $\mathrm{H}_{0}$ dengan persamaan garis regresi sebesar $49.55+0,29 X$.

\section{DAFTAR PUSTAKA}

Al-Qur'anul Karim

Abu Ahmadi dan Nur Uhbiayti, (2001), Ilmu Pendidikan, Jakarta: Rineka Cipta.

Abdurrahman. (1993). Pengelolaan Pengajaran. Ujung Pandang: PT. Bintang Selatan.

Agus Nggermanto, (2003), Quantum Quantient, Kecerdasan Quantum, Bandung, Nuansa.

Cholid Narbako \& Abu Achmadi, (2004). Metodologi Penelitian, Jakarta:Bumi Aksara.

Doni ANwar. (2016). Penerapan model pembelaran MURDER dalam meningkatkan daya ingat siswa belajar Fiqih di MTs Bandar Lampung. Skripsi Fakultas Ilmu Tarbiyah dan Keguruan Universitas Islam Negeri Raden Intan Lampung: Bandar Lampung.

E Mulyasa. (2009). Praktik Penelitian Tindakan Kelas. Bandung : PT. Remaja Rosdakarya.

Imam Nawawi, (2008), Terjemah Riandhus Shalihin Jilid I, Jakarta: Pussaka Assalam.

Muhammad Anwari. (2011). Penerapan Metode MURDERKekuatan Berdua) untuk Meningkatkan Kemampuan Belajar Kolaborasi dan Minat Siswa pada Materi Sistem Pencernaan Makanan di Kelas XI IPA MAN. Skripsi Fakultas Ilmu Tarbiyah dan Keguruan UIN Syarif Hidayatullah: Jakarta. 
Cybernetics: Journal Educational Research and Social Studies

Muhammad Arif Hidayat, (2017), The Evalution Of Learning.

Medan:Perdana Publishing.

Muhaimin, (2005), Pengembangan Kurikulum Pendidikan Islam, Jakarta : Raja Grafindo Persada.

Mulyono Abdurrahman, ( 2003), Pendidikan bagi anak berkesulitan belajar,

Jakarta : Rineka cipta.

Murodi, (2009), Sejarah Kebudayaan Islam Madrasah Tsanawiyah kelas VII, Semarang: PT. Karya Toha Putra.

Norman, (2012), Strategi Pembelajaran, Jakarta: Insan Cipta.

Ridwan, (2010), Belajar Mudah Penelitian, Bandung:Alfabeta 